Ferrata Storti Foundation

\title{
Expanded circulating hematopoietic stem/ progenitor cells as novel cell source for the treatment of TCIRG1 osteopetrosis
}

\author{
Valentina Capo, ${ }^{1}$ Sara Penna, ${ }^{1,2}$ Ivan Merelli, ${ }^{3}$ Matteo Barcella, ${ }^{1}$ Serena Scala, ${ }^{1}$ \\ Luca Basso-Ricci, ${ }^{1}$ Elena Draghici, ${ }^{1}$ Eleonora Palagano, ${ }^{4,5}$ Erika Zonari, ${ }^{1}$ \\ Giacomo Desantis, ${ }^{1}$ Paolo Uva, ${ }^{6}$ Roberto Cusano, ${ }^{6}$ Lucia Sergi Sergi, ${ }^{1}$ \\ Laura Crisafulli, ${ }^{4,5}$ Despina Moshous, ${ }^{7,8}$ Polina Stepensky, ${ }^{9}$ \\ Katarzyna Drabko, ${ }^{10}$ Zühre Kaya, ${ }^{11}$ Ekrem Unal, ${ }^{12,13}$ Alper Gezdiric, ${ }^{14}$ \\ Giuseppe Menna, ${ }^{15}$ Marta Serafini, ${ }^{2}$ Alessandro Aiuti, ${ }^{1}$ Silvia Laura Locatelli, ${ }^{16}$ \\ Carmelo Carlo-Stella, ${ }^{16,17}$ Ansgar S. Schulz, ${ }^{18}$ Francesca Ficara, ${ }^{4,5}$ \\ Cristina Sobacchi, ${ }^{4,5}$ Bernhard Gentner ${ }^{1}$ and Anna Villa ${ }^{1,4}$
}

Haematologica 2021

Volume 106(1):74-86

${ }^{1}$ San Raffaele Telethon Institute for Gene Therapy (SR-Tiget), IRCCS San Raffaele Scientific Institute, Milan, Italy; ${ }^{2}$ DIMET, University of Milano-Bicocca, Monza, Italy; ${ }^{3}$ Institute for Biomedical Technologies, National Research Council, Segrate, Italy;

${ }^{4}$ CNR-IRGB, Milan Unit, Milan, Italy; ${ }^{5}$ Humanitas Clinical and Research Center - IRCCS, Rozzano, Italy; ${ }^{6} \mathrm{CRS} 4$, Science and Technology Park Polaris, Pula, Italy;

'Unité d'Immunologie, Hématologie et Rhumatologie Pédiatriques (UIHR), Assistance Publique-Hôpitaux de Paris, Hôpital Necker-Enfants Malades, Paris, France; ${ }^{8}$ INSERM UMR1163, Institut Imagine, Université Paris Descartes-Sorbonne Paris Cité, Paris, France; ${ }^{9}$ Department of Bone Marrow Transplantation and Cancer Immunotherapy, Hadassah University Hospital, Jerusalem, Israel; ${ }^{10}$ Medical University of Lublin, Lublin, Poland; ${ }^{11}$ Department of Pediatric Hematology, Gazi University, School of Medicine, Ankara, Turkey; ${ }^{12}$ Erciyes University, Pediatric Hematology Oncology, Kayseri, Turkey; ${ }^{13}$ Molecular Biology and Genetic Department, Gevher Nesibe Genom and Stem Cell Institution, Genome and Stem Cell Center (GENKOK), Erciyes University, Kayseri, Turkey; ${ }^{14}$ Department of Medical Genetics, Istanbul Health Science University, Kanuni Sultan Suleyman Training and Research Hospital, Istanbul, Turkey; ${ }^{15} \mathrm{Hemato}$-Oncology Unit, Department of Oncology, Pausilipon Hospital, Naples, Italy; ${ }^{16}$ Department of Oncology and Hematology, Humanitas Cancer Center, Humanitas Clinical and Research Center, Rozzano, Italy; ${ }^{17}$ Department of Biomedical Sciences, Humanitas University, Rozzano, Italy and ${ }^{18}$ Department of Pediatrics and Adolescent Medicine, University Medical Center, Ulm, Germany

\section{ABSTRACT}

\section{Correspondence:}

ANNA VILLA

villa.anna@hsr.it

Received: September 14, 2019.

Accepted: January 9, 2020.

Pre-published: January 16, 2020.

https://doi.org/10.3324/haematol.2019.238261

(C)2021 Ferrata Storti Foundation

Material published in Haematologica is covered by copyright. All rights are reserved to the Ferrata Storti Foundation. Use of published material is allowed under the following terms and conditions:

https://creativecommons.org/licenses/by-nc/4.0/legalcode. Copies of published material are allowed for personal or internal use. Sharing published material for non-commercial purposes is subject to the following conditions:

https://creativecommons.org/licenses/by-nc/4.0/legalcode, sect. 3. Reproducing and sharing published material for commercial purposes is not allowed without permission in writing from the publisher.

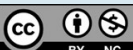

A llogeneic hematopoietic stem cell transplantation is the treatment of choice for autosomal recessive osteopetrosis caused by defects in the TCIRG1 gene. Despite recent progress in conditioning, an important number of patients are not eligible for allogeneic stem cell transplantation because of the severity of the disease and significant transplant-related morbidity. We exploited peripheral CD34+ cells, known to circulate at high frequency in the peripheral blood of TCIRG1-deficient patients, as a novel cell source for autologous transplantation of gene corrected cells. Detailed phenotypical analysis showed that circulating $\mathrm{CD} 34^{+}$cells have a cellular composition that resembles bone marrow (BM), supporting their use in gene therapy protocols. Transcriptomic profile revealed enrichment in genes expressed by hematopoietic stem and progenitor cells (HSPC). To overcome the limit of BM harvest/HSPC mobilization and serial blood drawings in TCIRG1 patients, we applied UM171-based ex vivo expansion of HSPC coupled with lentiviral gene transfer. Circulating CD34+ cells from TCIRG1defective patients were transduced with a clinically-optimized lentiviral vector expressing TCIRG1 under the control of phosphoglycerate promoter and expanded ex vivo. Expanded cells maintained long-term engraftment capacity and multi-lineage repopulating potential when transplanted in vivo both in primary and secondary NOD scid gamma common chain (NSG) recipients. Moreover, when ${\mathrm{CD} 34^{+}}^{+}$cells were differentiated in vitro, genetically corrected osteoclasts resorbed the bone efficiently. Overall, we provide evidence that expansion of circulating HSPC coupled to gene therapy can overcome the limit of stem cell harvest in osteopetrotic patients, thus opening the way to future gene-based treatment of skeletal diseases caused by BM fibrosis. 


\section{Introduction}

Autosomal recessive osteopetrosis (ARO) is a rare and heterogeneous genetic disease, caused by defects in the differentiation or resorption activity of osteoclasts. Patients present with dense and brittle bones, severe anemia, hepatosplenomegaly, macrocephaly, progressive deafness and blindness due to pressure on nerves, and limited bone marrow (BM) cavities. ${ }^{1,2}$ The incidence of the disease is 1 in 250,000 live births, with higher rates in specific geographic areas where consanguineous marriages are frequent. ${ }^{3}$ More than $50 \%$ of the cases are due to defects in the TCIRG1 gene, encoding for the a3 subunit of ATPase $\mathrm{H}^{+}$transporting V0 complex, necessary for the acidification of organelles and resorption lacuna. ${ }^{4}$

The disease is usually lethal in the first decade of life, with poor quality of life. To date, the only curative treatment is hematopoietic stem cell transplantation (HSCT) from an allogeneic donor, which has to be performed as early as possible before compression of nerves and irreversible neurological damage has occurred. ${ }^{5,6}$ Children with osteopetrosis suffer from high rates of graft failure and transplant-related mortality, mostly due to severe graft-versus-host disease, liver toxicity (veno-occlusive disease), infections or lung toxicity (idiopathic pneumonia syndrome and acute respiratory distress syndrome), ${ }^{7,8}$ In particular, transplants from HLA-matched related or unrelated donors have an 80-88\% 5-year disease-free survival, whereas the success rate is lower for haploidentical transplants $(66 \%))^{2}$ Recently, improvements in the outcome and overall survival have been observed in patients treated with fludarabine-based conditioning regimens and T-cell depleted haploidentical donors.,10 However, HLA-compatible donors are readily available only to a minority of patients. Umbilical cord blood transplantation (UCBT) has also been used as an alternative source, but overall survival at 6 years was $43 \%$, so it is no longer recommended. ${ }^{11}$

To overcome donor-related issues, gene therapy has been proposed as an alternative strategy. In the past, a retroviral vector, in which the TCIRG1 gene was driven by the strong viral SFFV (spleen focus-forming virus) promoter, has been tested in oc/oc mice, the murine model of TCIRG1-deficient osteopetrosis, ${ }^{12}$ showing that ex vivo gene therapy for ARO is effective. More recently, TCIRG1-expressing lentiviral vectors, driven by different promoters, were designed and tested in ARO CD34 cells in vitro and in the ocloc mouse model. ${ }^{13-15}$ Since BM harvest cannot be performed in these patients due to severe BM fibrosis and susceptibility to bone fractures, peripheral blood (PB) $\mathrm{CD} 34^{+}$cells represent a potential source of autologous hematopoietic stem and progenitor cells (HSPC). The majority of ARO patients have high frequencies of circulating $\mathrm{CD} 34^{+}$cells, because of the limited BM cavities and the reduction of hematopoietic stem cell (HSC) niches. ${ }^{16,17}$ Of note, previous studies showed that $\mathrm{PB}$ of osteopetrotic patients is highly enriched in cells with myeloid and erythroid clonogenic potential. ${ }^{16,18}$ However, there is still no detailed characterization of ARO $\mathrm{PB} \mathrm{CD} 34^{+}$cell stemness markers, a prerequisite before considering their clinical use.

Finally, despite the high frequency of $\mathrm{PB} \mathrm{CD} 34^{+}$cells, the amount of collectable HSPC for ex vivo manipulation is constrained by the severity of the disease, the young age of the patients, and the small quantity of blood that can be drawn. Data reported in literature indicate the feasibility of exchange transfusion in osteopetrotic patients as back- up. ${ }^{16}$ Since gene therapy protocols usually require higher amounts of $\mathrm{CD} 34^{+}$cell $/ \mathrm{kg}$, we might speculate that an adequate number of autologous $\mathrm{CD} 34^{+}$cells can be obtained through the collection of both spontaneously circulating and mobilized HSPC. We hypothesized that an efficient expansion of short-term progenitors and HSC may promote the collection of an adequate cell dose, allowing timely hematopoietic recovery and durable engraftment by genetically-engineered cells, respectively. To this end, we tested an HSPC expansion protocol previously used for cord blood (CB), BM or mobilized PB $\mathrm{CD}_{4} 4^{+}$cells from healthy donors. ${ }^{19,20} \mathrm{We}$ exploited the pyrimidoindole derivative UM171 to expand ARO-derived $\mathrm{PB} C D 34^{+}$cells with repopulating potential, after transduction with a clinically optimized TCIRG1-expressing lentiviral vector driven by the phosphoglycerate kinase (PGK1) promoter. We demonstrated that transduced and expanded cells generated functional bone-resorbing osteoclasts in vitro. Our deep phenotypic characterization revealed that ARO-derived spontaneously mobilized $\mathrm{CD} 4^{+}$cells contained bona fide primitive HSC, and that the stem cell output and BM homing capacity were maintained in NOD scid gamma common chain (NSG) mice after the expansion protocol. Overall, we have established a novel protocol that will allow transplantation of gene-corrected and expanded $\mathrm{PB} \mathrm{CD} 34^{+}$cells in human disorders characterized by BM fibrosis.

\section{Methods}

\section{Patients and healthy donors}

Peripheral blood of ARO patients and healthy donors was obtained according to the Declaration of Helsinki with the approval of the local medical ethical committees. A description of patients is provided in Table 1 . ARO17 and ARO18 patients have been previously described (patients 13 and 19, respectively). ${ }^{21}$ Details on healthy donors are reported in the Online Supplementary Methods.

\section{CD34 ${ }^{+}$isolation and culture}

A Lymphoprep (STEMCELL Technologies) density gradient was used to isolate PB mononuclear cells (PBMC). CD34 ${ }^{+}$cells were isolated from PBMC using human CD34 MicroBead Kit and autoMACS Pro Separator (Miltenyi Biotec), according to the manufacturer's instructions. CD34 ${ }^{+}$were pre-stimulated for 24 hours (h) and transduced with 1-hit of LV at MOI 100 overnight, as previously described. ${ }^{22,23}$ Hematopoietic progenitor cultures were performed plating 2,500 cells in $2.5 \mathrm{~mL}$ MethoCult H4434 Classic methylcellulose-based medium (STEMCELL Technologies) and cultured for 12 days.

After transduction, cells were expanded using UM171 compound until day 7 , as previously described. ${ }^{19}$ A fraction of expanded cells was differentiated in vitro towards the myeloid lineage for 1 week and then into osteoclasts for 2 or 3 weeks on plastic wells or bone slices (Immunodiagnostic Systems), as previously described. ${ }^{14}$

\section{Mice}

Animal experimental procedures were approved by the Institutional Animal Care and Use Committee of San Raffaele Hospital and the Italian Ministry of Health. NOD scid gamma common chain (NSG) mice, obtained from Charles River Laboratories, were irradiated at $180 \mathrm{RAD}$ and transplanted after $2 \mathrm{~h}$, as detailed in Online Supplementary Table S1. 


\section{RNAsequencing}

Total RNA of CD34 $4^{+}$cells was extracted using ReliaPrep RNA Cell Miniprep System (Promega), according to the manufacturer's instructions. Library generation and data analysis were performed as detailed in the Online Supplementary Methods.

\section{Osteoclast activity}

Osteoclasts cultured on plastic were stained using the Tartrate Resistant Acid Phosphatase (TRAP) Kit (Sigma-Aldrich), following the manufacturer's instructions. Osteoclasts differentiated on bone slices were stained using alendronate conjugated to Alexa Fluor 488, ${ }^{24}$ TRITC-conjugated phalloidin (Sigma-Aldrich) and TO-PRO-3 (Thermo Fisher Scientific). To evaluate bone resorption, the same bone slices were used for toluidine blue staining as previously described. ${ }^{25}$ TRAP and toluidine blue images were acquired on a Zeiss AxioImager M2m microscope, while immunofluorescence staining images were acquired on a Leica TCS SP5 Laser Scanning Confocal microscope.

Quantification of CTX-I was performed on culture supernatants using CrossLaps for Culture (CTX-I) ELISA

Table 1. Patients' characteristics.

\begin{tabular}{|c|c|c|c|c|c|c|c|}
\hline Patient & Sample type & Age & TCIRG1 mutation & $\%$ CD34 in WB & CD34+/UL & $\begin{array}{c}\text { Blood } \\
\text { volume (mL) }\end{array}$ & $\begin{array}{l}\text { Isolated } \\
\text { CD34 }\end{array}$ \\
\hline ARO2 & Peripheral blood & 5.5 months & $\begin{array}{l}\text { c.713+1G>A, r.spl; } \\
\text { c.1555-2A>C, r.spl }\end{array}$ & 4.97 & 1831 & 2.0 & $3.53 \mathrm{E}+05$ \\
\hline ARO6 & Frozen PBMC & 11 months & $\begin{array}{l}\text { c. } 1674-1 \mathrm{G}>\mathrm{A} \text {, r.spl; } \\
\text { c.1674-1G>A, r.spl }\end{array}$ & 0.94 & na & na & $2.20 \mathrm{E}+04$ \\
\hline ARO7 & Peripheral blood & 8 months & $\begin{array}{l}\text { с.2321C>G, p.(Pro774Arg); } \\
\text { c.2321C>G, p.(Pro774Arg) }\end{array}$ & 1.59 & 282 & 3.2 & $2.70 \mathrm{E}+05$ \\
\hline ARO9 & Frozen PBMC & 12 months & $\begin{array}{l}\text { c.1874-1G>A, r.spl; } \\
\text { c.1874-1G>A, r.spl }\end{array}$ & 4.26 & na & na & $5.00 \mathrm{E}+05$ \\
\hline AR012 & Frozen PBMC & 2 months & $\begin{array}{l}\text { c. } 2233+1 \mathrm{G}>\mathrm{A}, \text { r.spl; } \\
\text { c. } 2233+1 \mathrm{G}>\mathrm{A} \text {, r.spl }\end{array}$ & 7.52 & na & na & $1.30 \mathrm{E}+05$ \\
\hline AR013 & Peripheral blood & 5 months & $\begin{array}{l}\text { c. } 2233+1 \mathrm{G}>\mathrm{A} \text {, r.spl; } \\
\text { c. } 2233+1 \mathrm{G}>\mathrm{A} \text {, r.spl }\end{array}$ & 5.90 & 539 & 6.7 & $1.90 \mathrm{E}+05$ \\
\hline ARO16 & Frozen PBMC & 10 months & $\begin{array}{l}\text { c. } 2233+1 \mathrm{G}>\mathrm{A}, \mathrm{r} . \mathrm{spl} \\
\text { c. } 2233+1 \mathrm{G}>\mathrm{A}, \mathrm{r} . \mathrm{spl}\end{array}$ & 1.93 & na & na & $2.00 \mathrm{E}+05$ \\
\hline ARO17 & Frozen PBMC & 7 months & $\begin{array}{l}\text { c. } 1875 \text { C>A, p.(Tyr625X); } \\
\text { c.1875C>A, p.(Tyr625X) }\end{array}$ & 1.61 & na & na & $1.60 \mathrm{E}+05$ \\
\hline AR018 & Frozen PBMC & 7 months & $\begin{array}{l}\text { c.1228G >A, p.(Gly410Arg); } \\
\text { c.2374G>C, p.(Gly792Arg) }\end{array}$ & 8.91 & na & na & $1.16 \mathrm{E}+06$ \\
\hline \multirow[t]{2}{*}{ ARO19 } & Peripheral blood & 12 months & $\begin{array}{l}\text { r.223_224inst; } \\
\text { r.223_224inst }\end{array}$ & 2.90 & 1466 & 6.0 & $1.89 \mathrm{E}+06$ \\
\hline & Peripheral blood & 13 months & & & & 8.8 & $1.08 \mathrm{E}+06$ \\
\hline ARO20 & Peripheral blood & 7 months & $\begin{array}{l}\text { c.2005C>T, p.(Arg669X); } \\
\text { r.694_695insa }\end{array}$ & 0.10 & 25 & 7.0 & 4.10E+05 \\
\hline ARO21 & Peripheral blood & 2.5 months & $\begin{array}{l}\text { c.1682delinsTT, } \\
\text { p.(Gly561Valfs); } \\
\text { c.2383_2384del, } \\
\text { p.(Ala796Leufs) }\end{array}$ & 14.45 & 19 & 4 & $8.00 \mathrm{E}+05$ \\
\hline ARO25 & $\begin{array}{l}\text { Frozen PBMC } \\
\text { Peripheral blood }\end{array}$ & $\begin{array}{l}3.5 \text { months } \\
5.5 \text { months }\end{array}$ & $\begin{array}{l}\text { g.8280_9560del; } \\
\text { g.8280_9560del }\end{array}$ & 6.70 & $\begin{array}{c}\text { na } \\
1353\end{array}$ & $\begin{array}{l}\text { na } \\
16.5\end{array}$ & $\begin{array}{l}1.02 \mathrm{E}+05 \\
1.11 \mathrm{E}+06\end{array}$ \\
\hline ARO26 & Peripheral blood & 8 months & $\begin{array}{l}\text { c.2218_2219del, } \\
\text { (p.Leu740Glufs); } \\
\text { c.2218_2219del, } \\
\text { (p.Leu740Glufs) }\end{array}$ & 4.07 & 899 & 5.6 & WBD only \\
\hline ARO27 & Peripheral blood & 8 months & c.1230del; c.1230del & 5.20 & 770 & 5.6 & WBD only \\
\hline ARO28 & Peripheral blood & 6 months & $\begin{array}{l}\text { c. } 1213 \mathrm{G}>\mathrm{A} \text {, } \\
\text { p. }(\mathrm{Gly} 405 \mathrm{Arg}) \\
\text { c. } 1674-1 \mathrm{G}>\mathrm{A} \text {, r.spl }\end{array}$ & 3.23 & 341 & 2.7 & WBD only \\
\hline ARO29 & Peripheral blood & 6.5 months & $\begin{array}{l}\text { c.1674-1G>A, } \\
\text { r.spl; c.1674-1G>A, r.spl }\end{array}$ & 2.40 & 458 & 3.0 & WBD only \\
\hline
\end{tabular}

PBMC: peripheral blood mononuclear cells; WB: whole blood; WBD: whole blood dissection analysis. na: not available. Accession number of the TCIRG1variant1 cDNA: NM_006019; the numbering used starts with nucleotide +1 for the A of the ATG-translation initiation codon. Sequence variant nomenclature conforms to the Human Genome Variation Society (HGVS) recommendations for the description of sequence variants. ${ }^{5}$ 
A

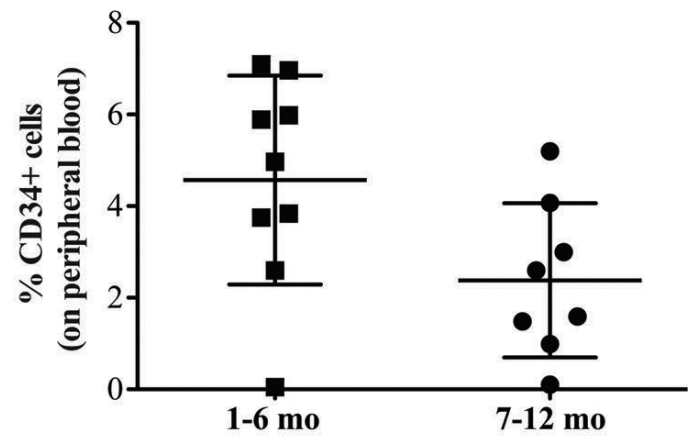

B
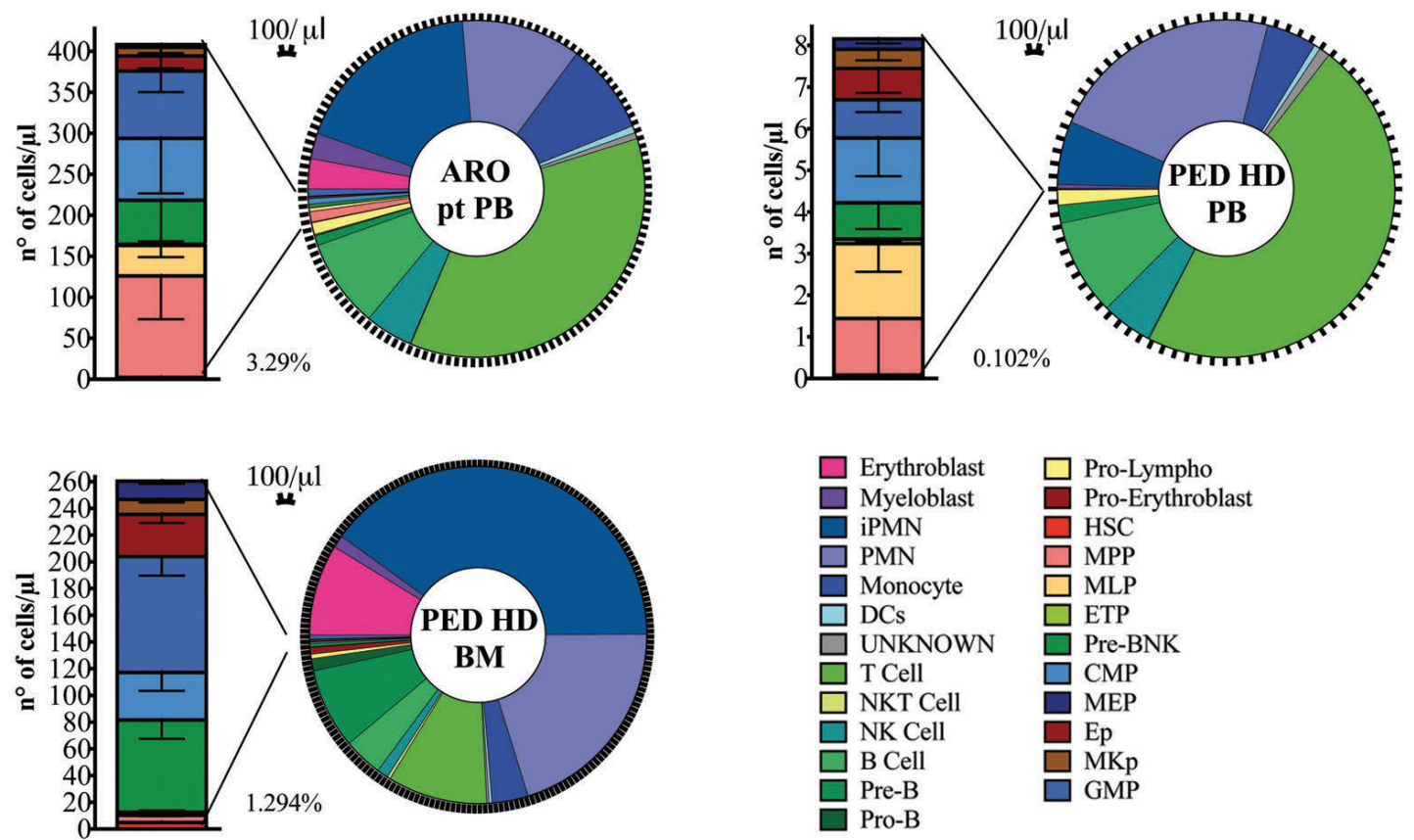

$\square$ Erythroblast
$\square$ Myeloblast
$\square$ iPMN
$\square$ PMN
$\square$ Monocyte
$\square$ DCs
$\square$ UNKNOWN
$\square$ T Cell
$\square$ NKT Cell
$\square$ NK Cell
$\square$ B Cell
$\square$ Pre-B
Pro-B

$\square$ Pro-Lympho
$\square$ Pro-Erythroblast
$\square$ HSC
$\square$ MPP
$\square$ MLP
$\square$ ETP
$\square$ Pre-BNK
$\square$ CMP
$\square$ MEP
$\square$ Ep
$\square$ MKp
$\square$ GMP

C

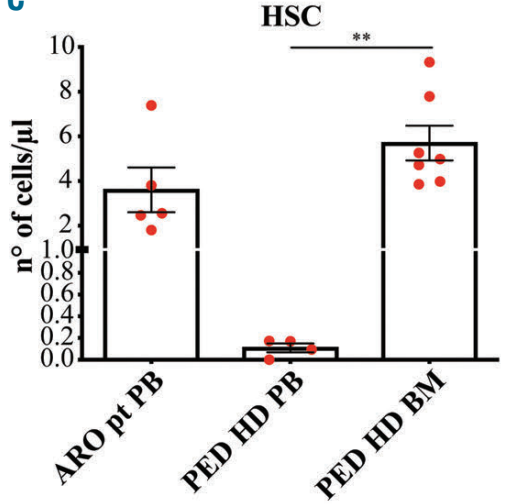

D

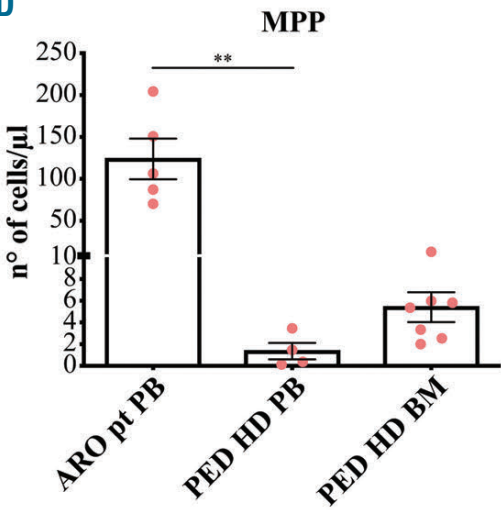

$\mathrm{E}$

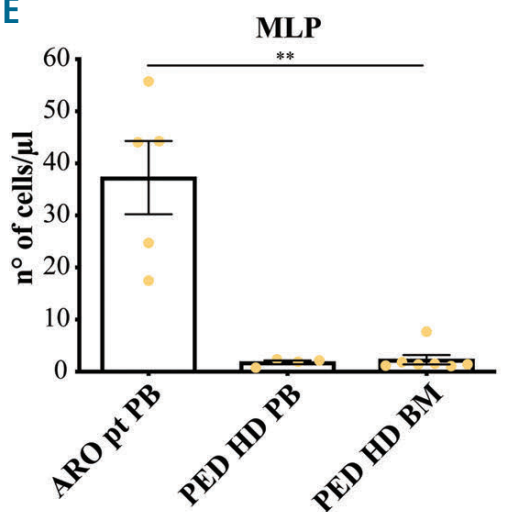

Figure 1. Circulating $C D 34^{+}$cells. (A) The graph shows the percentage of $C D 34^{+}$in the peripheral blood (PB) of ARO patients, divided in the indicated age groups. (B) Pie charts show distribution of 25 subsets within the CD45+ gate in ARO patient PB $(n=5)$, healthy donor PB $(n=4)$ and bone marrow $(B M)(n=7)$. Black outer ticks indicate 100 cells/ $\mu \mathrm{L}$. Percentages indicate the frequency of hematopoietic stem and progenitor cell (HSPC) population (CD34 $\left.{ }^{+} \mathrm{LIN}^{-}\right)$on total CD45 $5^{+}$cells. Stacked bar graphs indicate the absolute cell count/uL of the HSPC compartment, composed of ten primitive subsets: CMP: common myeloid progenitors; DC: dendritic cells; Ep: erythroid progenitors; ETP: early T progenitors; GMP: granulocyte-monocyte progenitors; HSC: hematopoietic stem cells; iPMN: immature polymorphonucleated cells; MEP: megakaryo-erythroid progenitors; MKp: megakaryocyte progenitors; MLP: multi-lymphoid progenitors; MPP: multipotent progenitors; NKT: natural killer-T cells; NK: natural killer cells; PMN: mature polymorphonucleated cells. (C-E) Graphs show cell count/uL of HSC (C), MPP (D), and MLP (E) in ARO patient PB, healthy donor PB and BM. Data show mean \pm standard deviation (A and B) or mean \pm standard error of mean (C-E). Statistical significance was determined by non-parametric Mann Whitney test (A) or Kruskal-Wallis test with Dunn's multiple comparison post test (C-E). 
A

Principal Component Analysis (PCA)
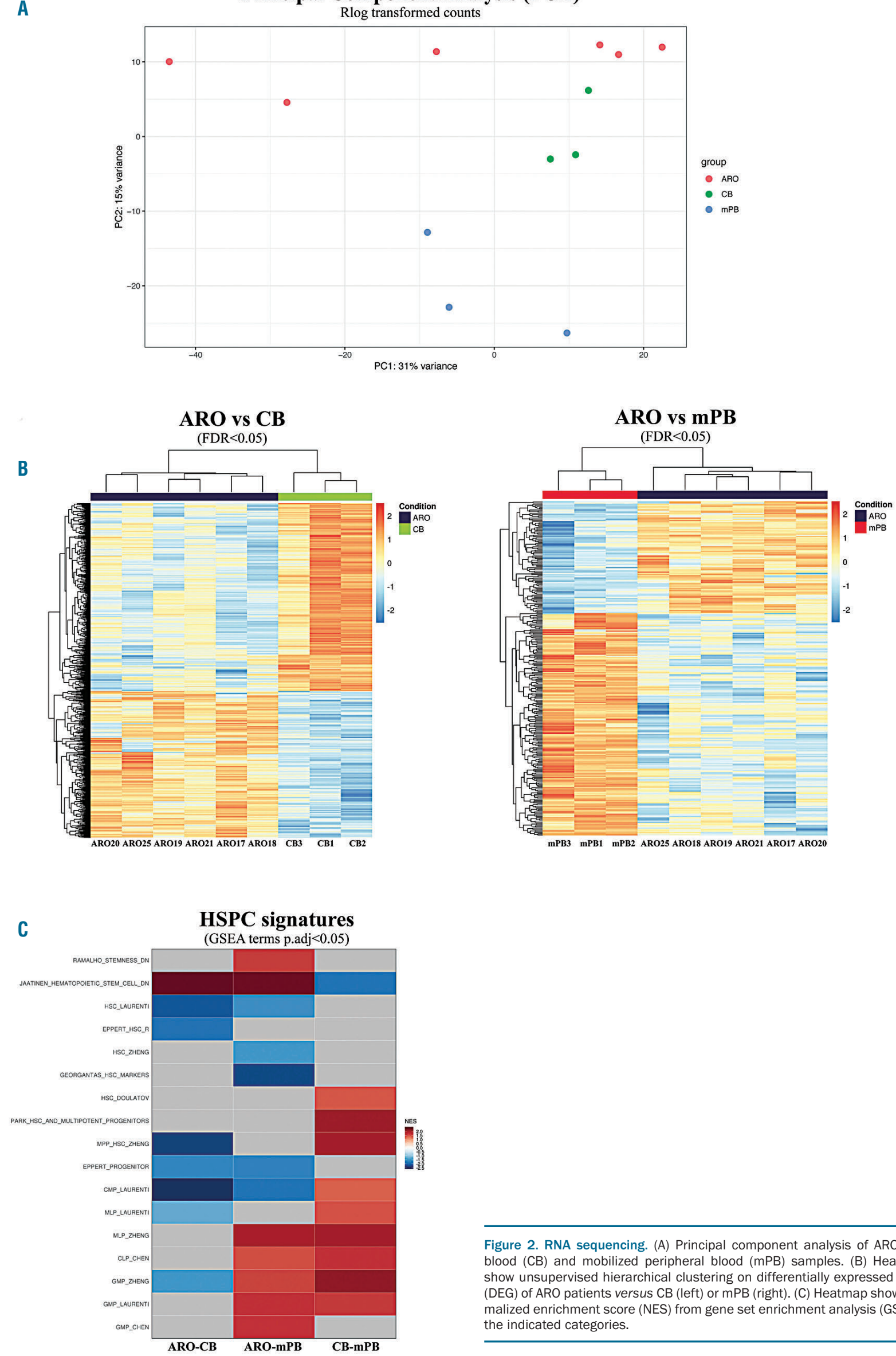

Figure 2. RNA sequencing. (A) Principal component analysis of ARO, cord blood (CB) and mobilized peripheral blood (mPB) samples. (B) Heatmaps show unsupervised hierarchical clustering on differentially expressed genes (DEG) of ARO patients versus CB (left) or mPB (right). (C) Heatmap shows normalized enrichment score (NES) from gene set enrichment analysis (GSEA) in the indicated categories. 
A

PGK.TCIRG1

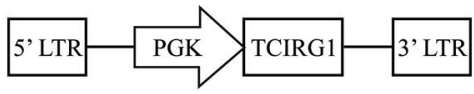

PGK.TCIRG1/dNGFR 5'LTR dNGFR CMV PGK TCIRG1 3'

B

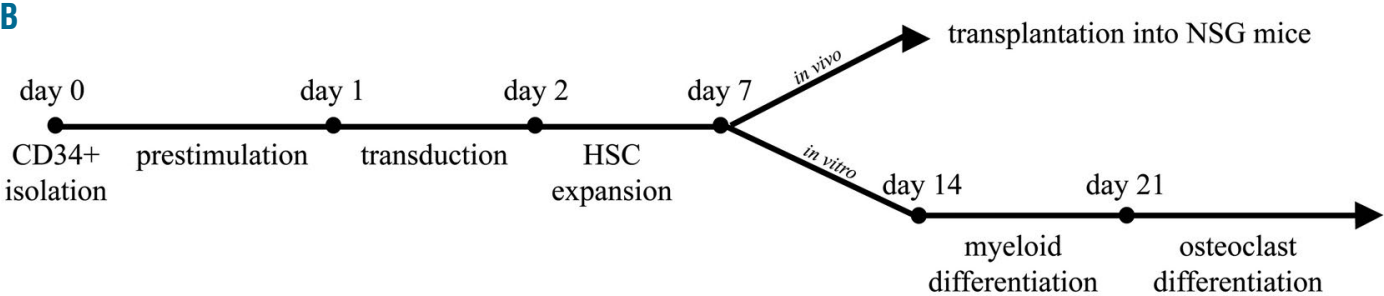

C

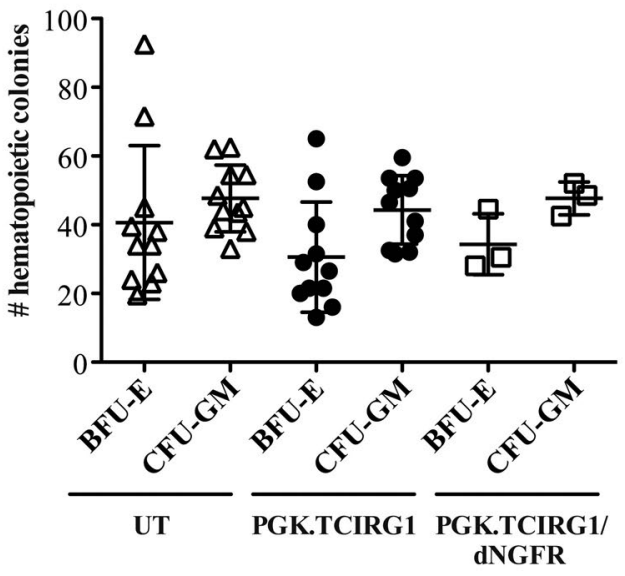

Figure 3. Transduction and expansion. (A) Schematic representation of the two vector constructs driving TCIRG1 expression: the PGK.TCIRG1 vector and PGK.TCIRG1/dNGFR bidirectional vector. LTR: long terminal repeat; PGK: phosphoglycerate kinase promoter; TCIRG1: T-cell immune regulator 1; dNGFR: deleted nerve growth factor receptor; CMV: cytomegalovirus promoter. (B) Time-line of transduction, expansion and in vivo and in vitro studies. (C) Absolute counts of hematopoietic progenitor colonies obtained in MethoCult cultures. BFU-E: burst-forming unit of erythroid cells; CFU-GM: colony-forming unit of granulocyte/macrophage. Data show mean \pm standard deviation.

(Immunodiagnostic Systems), according to the manufacturer's instructions.

\section{Statistical analysis}

Results are shown as mean \pm standard deviation (SD) or standard error of the mean (SEM). Statistical significance was determined by non-parametric Mann Whitney test, Kruskal-Wallis test, oneway ANOVA, two-way ANOVA, Dunn's post-test, Bonferroni post-test or Spearman correlation, as detailed in figure legends. ${ }^{*} P<0.05,{ }^{* *} P<0.01,{ }^{* * *} P<0.001,{ }^{* * * *} P<0.0001$.

Additional methods are presented in the Online Supplementary Methods.

\section{Results}

High number of circulating stem/progenitor cells in TCIRG1-defective autosomal recessive patients

Human HSPC are known to circulate at low frequencies in steady-state $\mathrm{PB}$ of healthy adult donors $(0.11 \% \pm 0.01){ }^{26}$ Interestingly, patients affected by TCIRG1-defective ARO show high $\mathrm{CD} 34^{+}$cell counts in the $\mathrm{PB},{ }^{16}$ due to the reduced BM cavities. To confirm this finding in our cohort of patients, we analyzed the frequencies of circulating $\mathrm{CD} 34^{+}$ cells in 17 TCIRG1-mutated patients. The vast majority had elevated $\mathrm{CD}_{3}{ }^{+}$frequencies, with age-dependent differences (Figure 1A). In particular, ARO patients under 6 months of age had a mean percentage of $4.57 \% \pm 2.3$, while children of $7-12$ months showed $2.38 \% \pm 1.7$ CD $34^{+}$cells.

We further characterized the composition of ARO PB
$\mathrm{CD}_{3} 4^{+}$cells by deep multi-parametric phenotyping, since

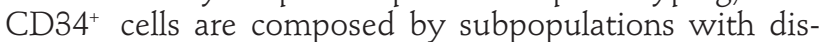
tinct differentiation and survival capability. Blood samples from five ARO patients (age range 5.5-8 months, mean 6.8 months) were analyzed using whole blood dissection (WBD) technology, a novel flow cytometry protocol, which evaluates and quantifies all major hematopoietic lineages including ten distinct HSPC subpopulations circulating in the periphery. ${ }^{27}$ As reference, we also analyzed $\mathrm{PB}$ samples from four age-matched pediatric healthy donors (age range: 4-7 months, mean: 5.3 months) and BM samples of seven pediatric healthy donors (age range: 3-17 years, mean: 10.5 years) (Figure $1 \mathrm{~B}$ ). The hematopoietic composition of PB from TCIRG1-deficient patients was more similar to pediatric BM than to PB from age-matched healthy children, as evidenced by the presence of classical BM-restricted progenitors such as erythroblasts, myeloblasts and B-cell progenitors (Online Supplementary Figure S1). Quantitative analysis of the absolute number/ $\mu \mathrm{L}$ of various HSPC subpopulations further confirmed similarities with BM. Importantly, we found that ARO patients display a content of primitive phenotypic

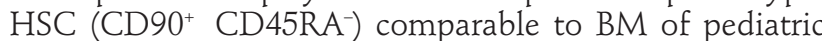
$\mathrm{HD}$ (Figure 1C). Additionally, ARO patients showed increased number of primitive multipotent progenitors (MPP) and multi-lymphoid progenitors (MLP) with respect to BM of healthy children and, most importantly, to the $\mathrm{PB}$ of healthy age-matched controls (Figure 1D and E).

Next, we performed whole trascriptome profiling through RNA sequencing (RNA-seq) to determine the 

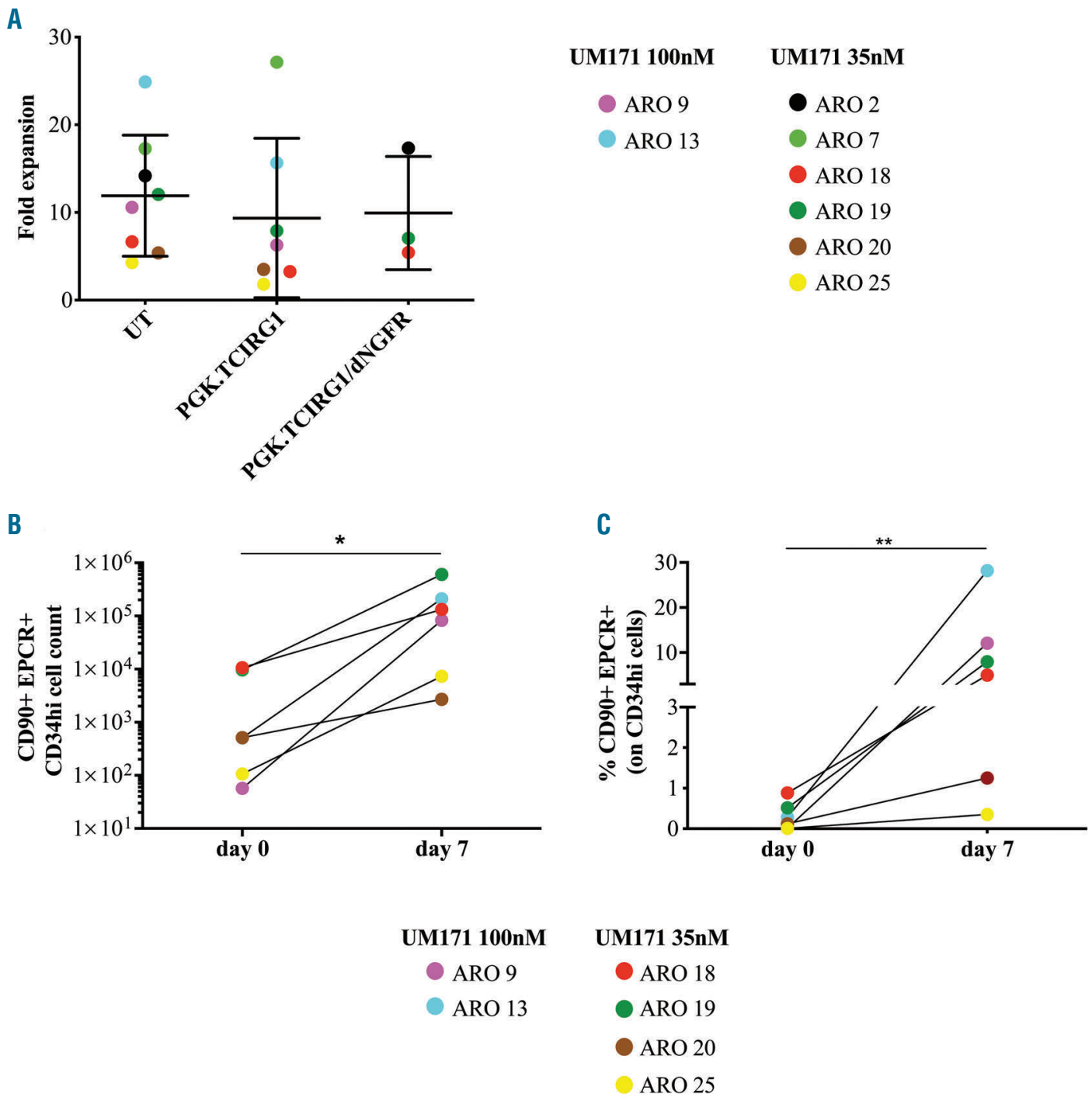

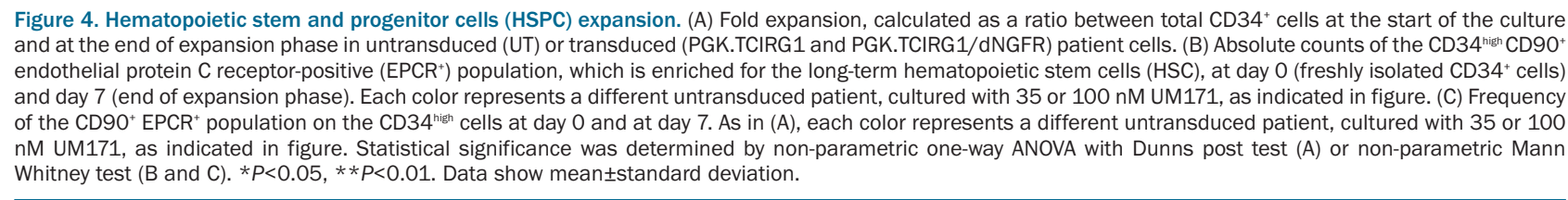

transcriptional signature of $\mathrm{ARO} \mathrm{CD}^{+} 4^{+}$cells, in comparison to $\mathrm{CD} 4^{+}$cells circulating in $\mathrm{CB}$ and mobilized $\mathrm{PB}$ (mPB) healthy donor cells, the two main sources for HSCT. Explorative data analysis performed by principal component analysis (PCA) revealed three clusters (ARO, $\mathrm{CB}$ and $\mathrm{mPB}$ ) corresponding to the cell source (Figure $2 \mathrm{~A}$ ). ARO samples are closer to $C B$ cell cluster rather than to $\mathrm{mPB}$. Using unsupervised hierarchical clustering on differentially expressed genes (DEG), ARO patients clustered together when compared to both $\mathrm{CB}$ and $\mathrm{mPB}$ (Figure $2 \mathrm{~B}$ and Online Supplementary Figure S2), confirming the unique nature of the osteopetrotic circulating $\mathrm{CD} 34^{+}$cells.

To study the HSPC composition at the RNA level, we used different gene lists reported in literature. ${ }^{28-36} \mathrm{Gene}$ set enrichment analysis (GSEA) revealed that ARO $\mathrm{CD}_{3} 4^{+}$ cells were enriched for committed progenitors (MLP, CLP and GMP) in comparison to $\mathrm{mPB}$, similarly to $\mathrm{CB}$. No definitive conclusions could be drawn on the most primitive HSC population, since heterogeneous results were obtained depending on the gene set used (Figure 2C).

Overall, these analyses confirmed that $\mathrm{CD} 34^{+}$cells are present at high numbers in the PB of TCIRG1-defective patients and that these cells are enriched for primitive subsets both phenotypically and transcriptionally, providing the first indication that unmobilized PB could be a suitable stem cell source for gene therapy.

\section{Transduction and expansion of TCIRG1-defective CD34+ cells}

We designed a gene therapy approach based on the transduction with TCIRG1-expressing LV coupled with a HSPC expansion protocol, to overcome the limitation 
A
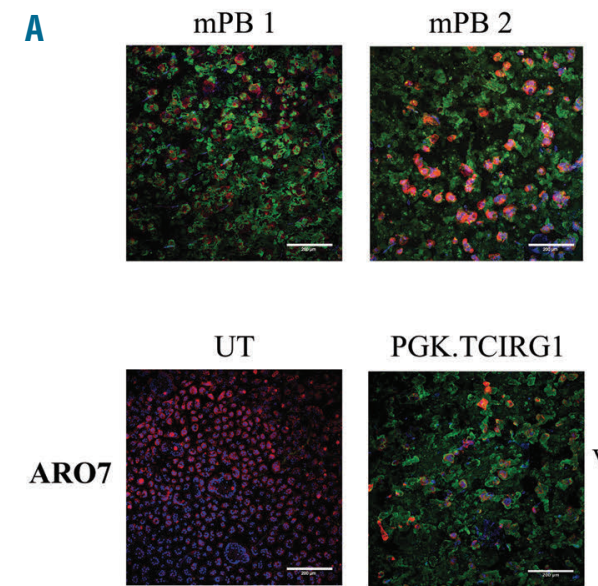

PGK.TCIRG1
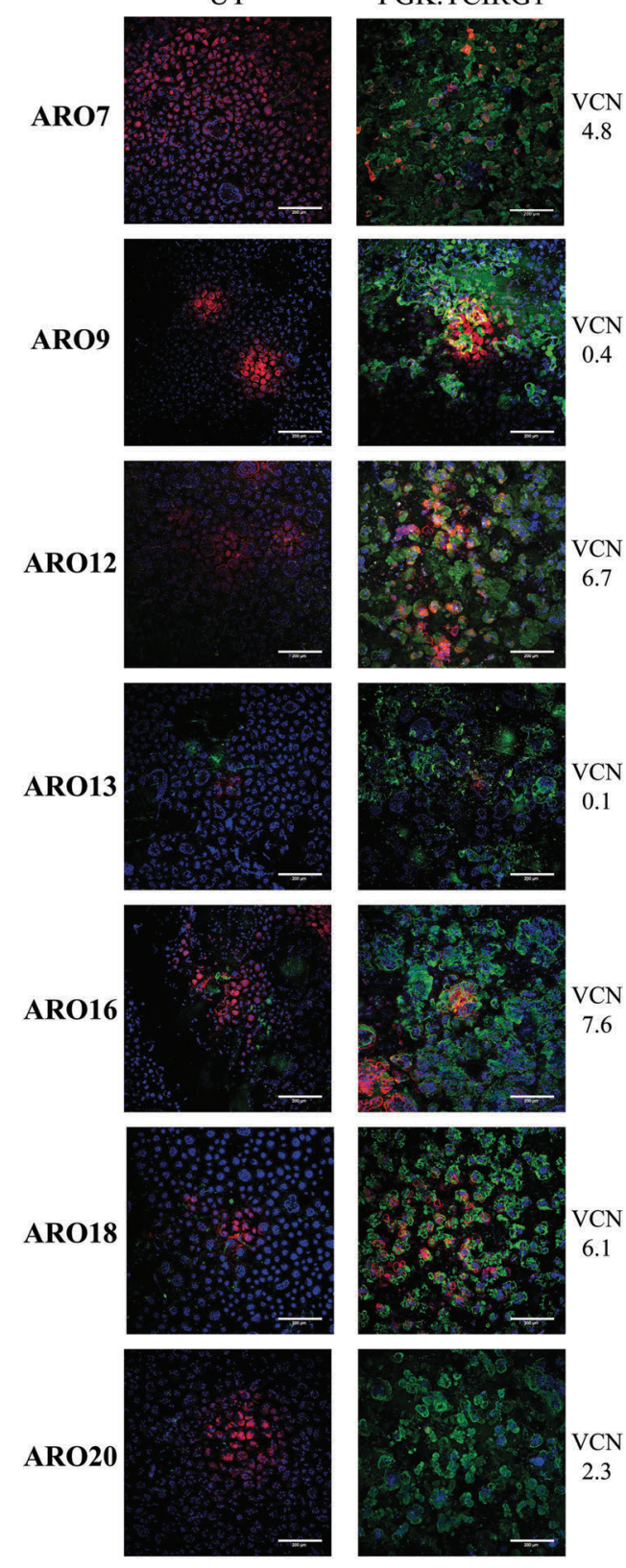

Alendronate Phalloidin TO-PRO-3

VCN

6.7

B

mPB 1

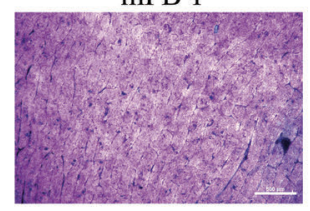

UT

ARO7

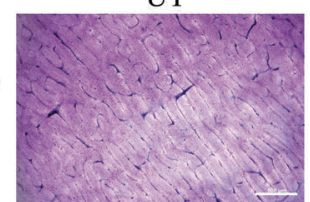

ARO9

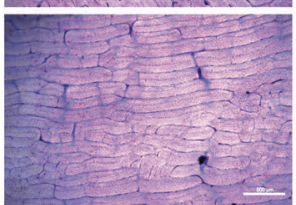

ARO12

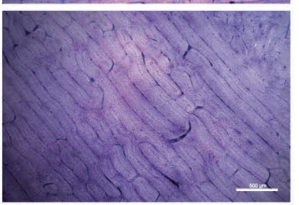

(n)

ARO20
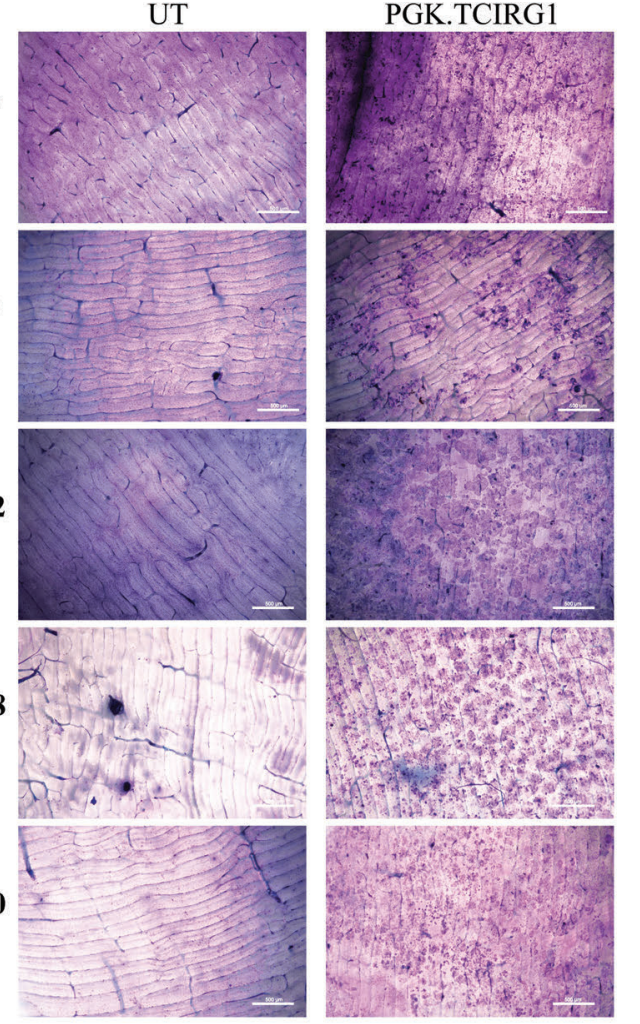

C

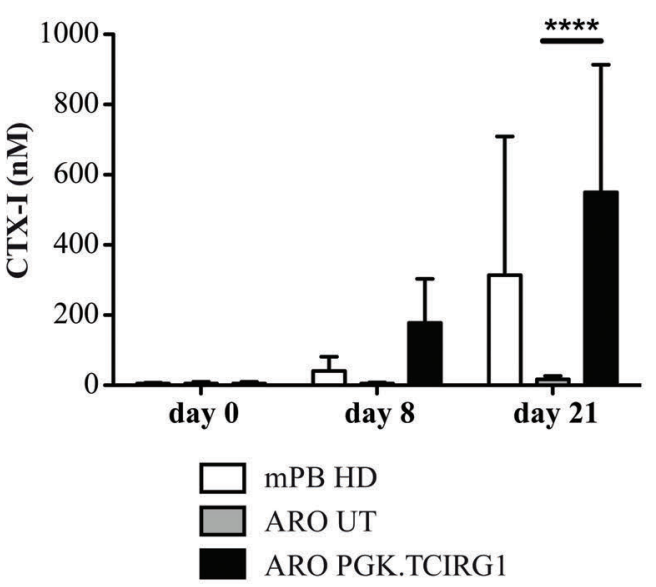

Figure 5. Osteoclast bone resorption. (A) Immunofluorescence staining of osteoclasts differentiated from CD34 cells and cultured on bone slices. Images show the merge result of alendronate-AF-488 (resorption pits in green), phalloidin-TRITC (actin rings in red) and TO-PRO-3 (nuclei in blue). (Top) Representative images of osteoclasts obtained from mobilized peripheral blood (mPB) CD34 ${ }^{+}$cells from two healthy donors. (Bottom) Representative images of untransduced (UT) or transduced (PGK.TCIRG1) osteoclasts from seven ARO patients. Vector copy numbers (VCN) of the transduced cells are indicated for each patient. Images were acquired with Leica TCS SP5 laser scanning confocal, equipped with HC PL FLUOTAR 10X (NA 0.3) dry and Leica Application Suite Advanced Fluorescence (LASAF) software. (B) Toluidine blue staining of bone slices that were previously cultured with osteoclasts from healthy donor mPB CD34 cells and ARO patient UT or transduced (PGK.TCIRG1) cells. VCN of the transduced cells are shown for each patient. Images were acquired with Nikon ECLIPSE E600 microscope equipped with Nikon DSRi2 camera, using Plan Fluor 4x/0.13 objective and NIS-Elements F 4.30 .01 software. (C) C-terminal telopeptide fragment of type I collagen (CTX-I) quantification in the osteoclast culture supernatant at day 0 , day 8, and day 21. Healthy donor mPB (mPB HD) CD34+ cells in white, ARO patient untransduced (ARO UT) cells in gray and ARO patient transduced (ARO PGK.TCIRG1) in black. Statistical significance was determined by two-way ANOVA with Bonferroni post-test (C). ****P<0.0001. All data show mean \pm standard. 
A

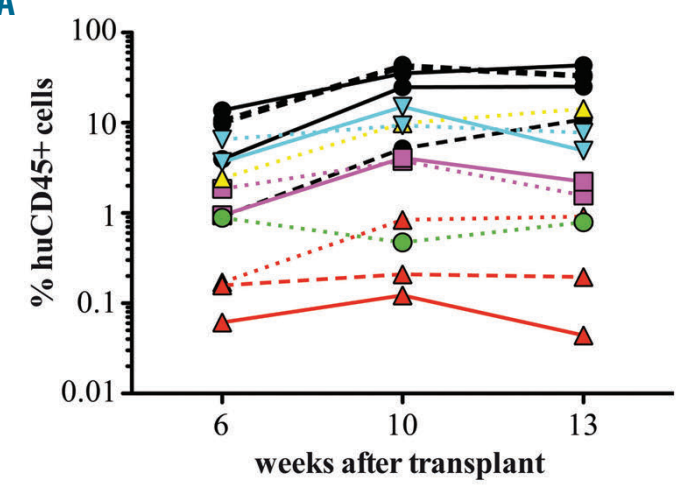

B

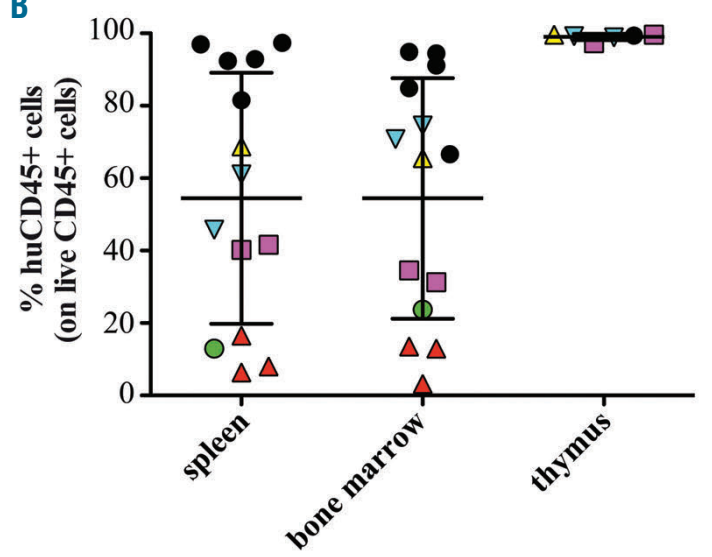

$$
\begin{aligned}
& \text { UM171 } 100 \mathrm{nM} \quad \text { UM17135 nM } \\
& \rightarrow \operatorname{ARO9}(\mathrm{n}=2) \longrightarrow \mathrm{ARO} 2(\mathrm{n}=5) \quad \longrightarrow \text { UT }
\end{aligned}
$$

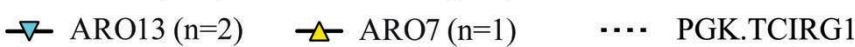

$$
\begin{aligned}
& \triangle \operatorname{ARO18(n=3)} \\
& \text { - } \mathrm{ARO} 25(\mathrm{n}=1)
\end{aligned}
$$

C

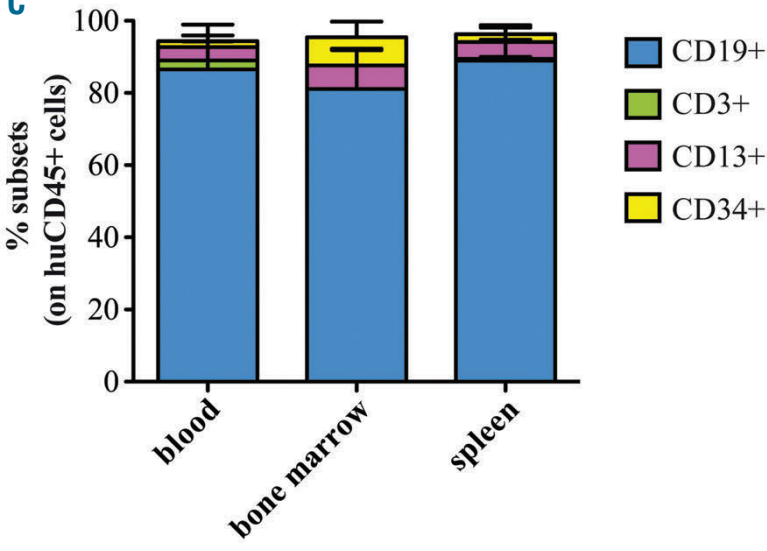

D

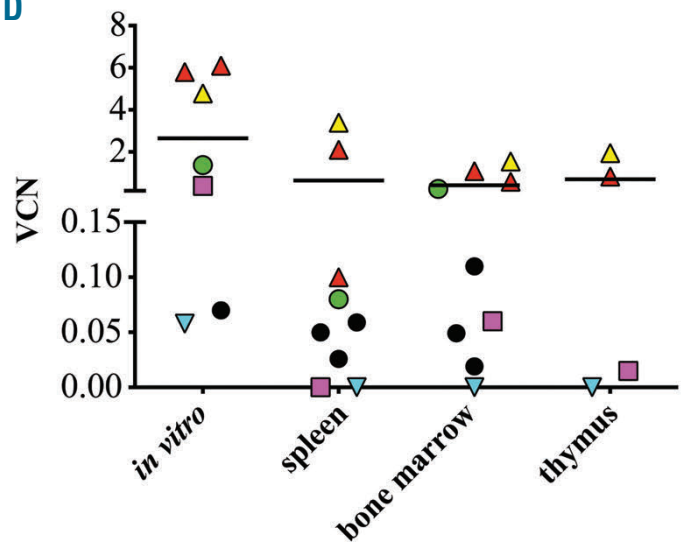

Figure 6. Transplants in primary NOD scid gamma common chain (NSG) recipients. (A) Percentage of human hematopoietic (huCD45 ${ }^{+}$) cells in the peripheral blood (PB) of primary NSG recipients over time. Each color represents a different patient, as indicated in figure. UM171 dosage used for CD34+ cell expansion is also indicated. Continuous line indicates untransduced (UT) cells, dotted line indicates cells transduced with PGK.TCIRG1 vector and dashed line indicates cells transduced with PGK.TCIRG1/dNGFR vector. (B) Percentage of human hematopoietic (huCD45 ) cells on total CD45 cells in spleen, bone marrow (BM) and thymus at sacrifice. (C) Percentage of CD19+(B lymphocytes, in blue), CD3 ${ }^{+}$(T lymphocytes, in green), CD13 (myeloid cells, in pink), and CD34 ${ }^{+}$(hematopoietic stem and progenitor cells, in yellow) subsets on the total human $\mathrm{CD}_{4} 5^{+}$cells. (D) Vector copy number (VCN) of in vitro transplanted cells and in tissues (spleen, BM and thymus). Data show mean $(A)$ or mean \pm standard deviation (B and $C)$.

imposed by the restricted amount of TCIRG1-defective $\mathrm{CD} 34^{+}$cells. In order to reduce the total culture period, we adapted the gene-correction protocol currently in use for gene therapy clinical trials, ${ }^{22,23}$ using only 1 hit of LV transduction.

We designed two different LV expressing TCIRG1 cDNA under the control of the phosphoglycerate kinase (PGK1) promoter (Figure 3A). The first vector (PGK.TCIRG1) was designed as a clinically-applicable vector, using the same backbone currently used in clinical trials. The second LV (PGK.TCIRG1/dNGFR) has a bidirectional design containing a marker gene, allowing easy detection/selection of transduced cells for research purposes. ${ }^{37}$

Circulating $\mathrm{CD}^{+} 4^{+}$cells, isolated from $2-16.5 \mathrm{~mL}$ of peripheral blood from 12 TCIRG1-mutated ARO patients (Table 1), were pre-stimulated with cytokines and then transduced either with PGK.TCIRG1 or PGK.TCIRG1/dNGFR (Figure 3B). Similar frequencies of burst-forming unit of erythroid cells (BFU-E) and colonyforming unit of granulocyte/macrophage (CFU-GM) colonies in transduced and non-transduced cells (Figure 3C) demonstrated that transduction did not impact on the clonogenic potential of HSPC.

To compensate for HSPC shortage and the difficulties in collecting them from the $\mathrm{PB}$ of very young patients, we exploited a recently described ex vivo expansion protocol based on UM171 small molecule..$^{19,20,38}$ After transduction, cells were expanded for 5 additional days in the presence of early-acting cytokines and the pyrimidoindole derivative UM171, reaching a total culture time of 7 days (Figure $3 \mathrm{~B})$, as practised in the UM171-based CB expansion trials. $^{39}$

In line with published data, ${ }^{38}$ UM171 exposure induced the expansion of the total $\mathrm{CD} 34^{+}$cells. We observed a 10.4-mean-fold expansion, with differences probably due to patient-to-patient variability, regardless of UM171 dose 
A

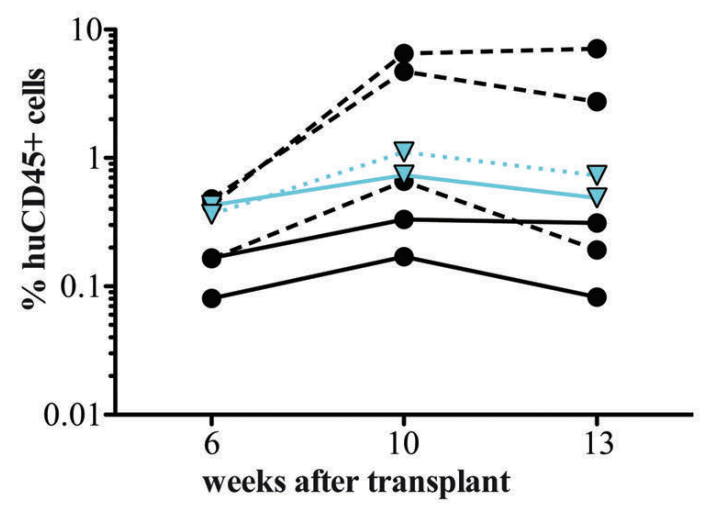

$\begin{array}{lll}\rightarrow \operatorname{ARO} 2(\mathrm{n}=5) & - & \text { UT } \\ \rightarrow-\operatorname{ARO} 13(\mathrm{n}=2) & \cdots & \text { PGK.TCIRG1 } \\ & -- & \text { PGK.TCIRG1/dNGFR }\end{array}$

C

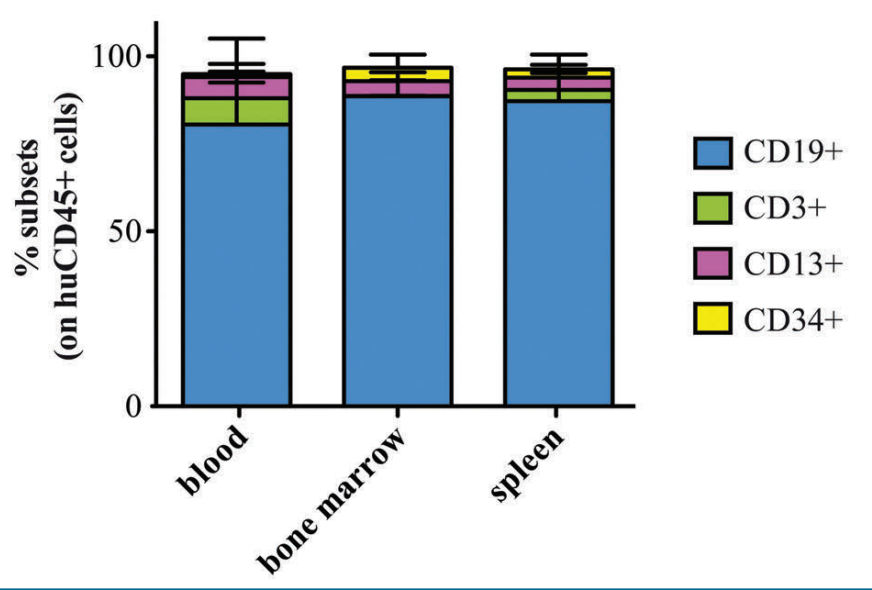

B

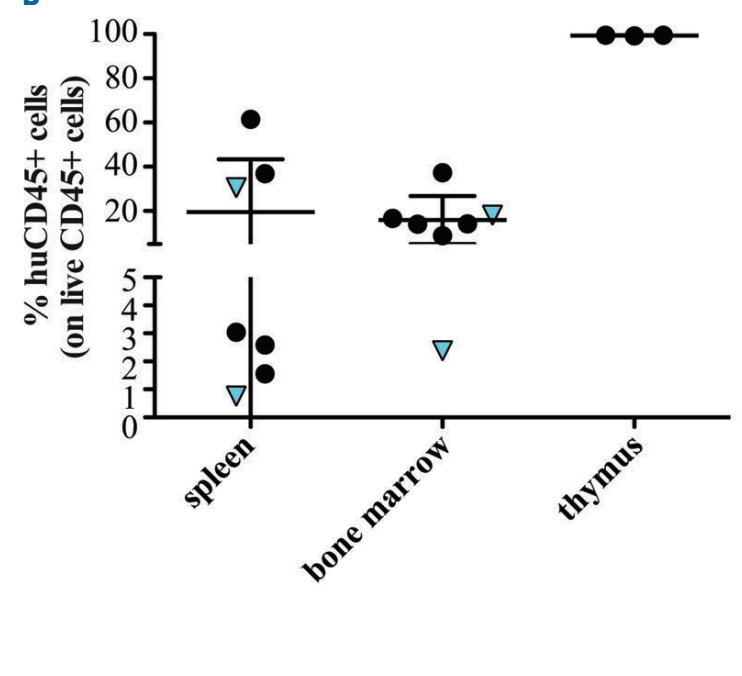

D

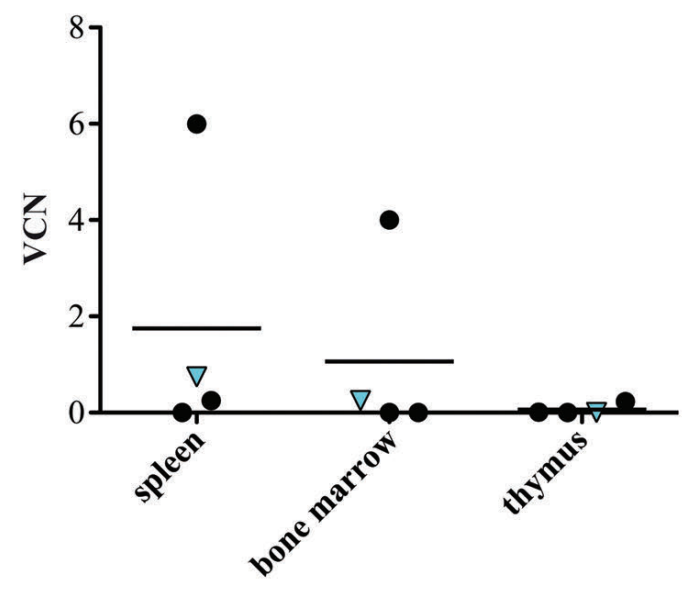

Figure 7. Transplants in secondary NOD scid gamma common chain (NSG) recipients. (A) Percentage of human hematopoietic (huCD45 ${ }^{+}$) cells in the peripheral blood (PB) of secondary NSG recipients over time. Each color represents a different patient, as indicated in figure. Continuous line indicates untransduced (UT) cells, dotted line indicates cells transduced with PGK.TCIRG1 vector and dashed line indicates cells transduced with PGK.TCIRG1/dNGFR vector. (B) Percentage of human hematopoietic (huCD45 ${ }^{+}$) cells on total CD45 cells in spleen, bone marrow (BM) and thymus at sacrifice. (C) Percentage of CD19+ $\left(B\right.$ lymphocytes, in blue), CD3 ${ }^{+}(T$ lymphocytes, in green), $\mathrm{CD}_{13}{ }^{+}$(myeloid cells, in pink), and CD34+ (hematopoietic stem and progenitor cells, in yellow) subsets on the total human CD45 cells. (D) Vector copy number (VCN) of in vitro transplanted cells and in tissues (spleen, BM and thymus). Data show mean (D) or mean \pm standard deviation (B and C).

(Figure 4A). Cells exposed to the TCIRG1-expressing LV showed a similar fold expansion as compared to their untransduced counterparts, confirming that UM171 expansion protocol can also be used in the setting of gene therapy. ${ }^{19}$ Importantly, the HSC-containing CD $34^{+}$CD $90^{+}$ endothelial protein $\mathrm{C}$ receptor-positive $\left(\mathrm{EPCR}^{+}\right)$cell subpopulation expanded both in terms of absolute counts (Figure 4B) and relative frequency within the CD34+ population (Figure 4C and Online Supplementary Figure S3A and $B$ ). The triple positive $\mathrm{CD} 34^{+} \mathrm{CD} 0^{+} \mathrm{EPCR}^{+}$population was present at comparable frequency in both transduced and untransduced cells (Online Supplementary Figure S3C).

\section{In vitro correction of osteoclast defect}

Transduced and expanded $\mathrm{CD} 34^{+}$cells were differentiated in vitro into myeloid progenitors and then into osteoclasts, in order to assess the correction of osteoclast resorptive function.

As expected, osteoclasts derived from TCIRG1-mutated patients were able to normally fuse and differentiate into mature, multinucleated, tartrate-resistant acid phosphatase (TRAP)-positive osteoclasts, although not functional (Online Supplementary Figure S4). We verified that osteoclasts from ARO patients did not express TCIRG1 protein. Transduction with the LV PGK.TCIRG1 restored the expression of the TCIRG1 protein, as assessed by western blot (Online Supplementary Figure S5).

To assess the functionality of gene-corrected cells, we cultured osteoclasts derived from untransduced and transduced patient cells on bone slices and analyzed the bone resorption by immunofluorescence and confocal microscopy after 2-3 weeks. The assembled nuclei (stained with TO-PRO-3) and the presence of actin rings (stained with phalloidin) confirmed osteoclast differentiation on the bone slices (Figure 5A). Untransduced patient cells were not able to resorb bone slices, as shown by the absence of alendronate-positive resorption pits. Conversely, gene-corrected patient-derived $\mathrm{CD}_{3} 4^{+}$were 
able to form fully functional osteoclasts, even at low vector copy number/genome (VCN). These findings were confirmed by toluidine blue staining, that was performed on bone slices after cell removal. Resorption pits were visible only on bone discs in the presence of patient corrected cells (Figure 5B). To quantify the resorption levels, we measured the C-terminal telopeptide fragment of type I collagen (CTX-I), a degradation marker of collagen released during bone and cartilage resorption. We quantified the CTX-I concentration in the culture supernatant at day 0 (start of the culture), at day 8 (intermediate time point), and at day 21 (end of the culture) by ELISA. Transduced patient cells resorbed bone slices at levels comparable to healthy donor cells at both days 8 and 21 . Conversely, untransduced patient cells were not able to resorb bone (Figure 5C). The CTX-I levels did not show a statistically significant correlation with the VCN, probably due to the variability of the osteoclast differentiation assay (Online Supplementary Figure S6). However, high levels of resorption were found also in cells with low VCN, supporting the hypothesis that osteoclasts may be functional even in case of a minor fraction of corrected nuclei.

\section{In vivo repopulating capacity of expanded $\mathrm{CD} 34^{+}$cells}

To evaluate the capability of gene-corrected ARO$\mathrm{CD} 34^{+}$cells to engraft and to fully differentiate in all hematopoietic lineages, we transplanted a median of $0.75 \times 10^{6}$ expanded CD34 $4^{+}$cells (range: $0.5-1 \times 10^{6}$ cells) in NSG mice, which corresponded to 0.11-0.47 day0 equivalents per mouse (Figure 3B and Online Supplementary Table S1). Mice were bled at 6 and 10 weeks, and euthanized at 13 weeks to study human cell engraftment. We observed the presence of stable human hematopoietic $\left(\mathrm{CD}^{+} 5^{+}\right)$multilineage cell engraftment in $\mathrm{PB}$, starting from 6 weeks after transplant (Figure 6A). The engraftment showed donor-dependent variability, not correlating with the transplanted day 0 equivalents, the transduction status of the cells, or the UM171 dosage.

At 13 weeks post transplant, we sacrificed the mice and analyzed the hematopoietic organs. In accordance to the results obtained in the $\mathrm{PB}$, we observed similar level of human $\mathrm{CD}_{4} 5^{+}$cell engraftment in the spleen and in the BM. In the thymus, nearly $100 \%$ of the cells were of human origin as expected (Figure 6B). The majority of human cells were $\mathrm{B}$ cells $\left(\mathrm{CD} 19^{+}\right)$as a consequence of the human cell differentiation bias in NSG mice. Nonetheless, we could observe the presence of myeloid $\left(\mathrm{CD} 13^{+}\right)$and $\mathrm{T}$ $\left(\mathrm{CD}^{+}\right)$cells in the hematopoietic organs and also of CD34+ HSPC in the BM (Figure 6C). Importantly, transduced cells were retrieved in the analyzed tissues, in line with the VCN of the in vitro cultures (Figure 6D), indicating long-term engraftment ability by TCIRG1-expressing HSPC.

After sacrifice of NSG mice, human CD34+ cells were re-isolated from the BM and transplanted in secondary NSG recipients. We isolated $0.7-1 \times 10^{6} \mathrm{CD} 34^{+}$cells from each mouse and transplanted them into a different recipient. We observed low but stable human engraftment overtime in secondary recipients up to 13 weeks after transplantation, indicating that our transduction and expansion strategy allowed the maintenance of long-term HSC (Figure 7A). Similarly to the results obtained in primary recipients, variable $\mathrm{CD} 45^{+}$frequencies were observed in the spleen and in the BM, whereas the thymus showed nearly $100 \%$ of human CD $45^{+}$cells (Figure 7B). In the sec- ondary grafts, multi-lineage cell repopulation was observed, with the expected prevalence of $\mathrm{CD} 19^{+}$cells $(\mathrm{B}$ lymphocytes) and the presence of $\mathrm{CD} 34^{+}$cells in the $\mathrm{BM}$ (Figure 7C). VCN in the hematopoietic organs was consistent with the transduction levels of the primary recipients (Figure 7D), indicating the long-term maintenance of genecorrected primitive HSPC.

\section{Discussion}

Up to now, hematopoietic stem cell transplantation has been the treatment of choice in patients with severe forms of autosomal recessive osteopetrosis, a rare genetic disease characterized by defective osteoclast function and BM fibrosis. Infusion of autologous gene corrected HSPC may represent an attractive therapy to avoid the risk of severe graft-versus-host-disease reactions and limit complications caused by intensive myeloablative conditioning. Gene therapy would also allow treatment of patients without compatible donors or whose severe clinical conditions and/or age preclude conventional therapy. ${ }^{7,40}$ In addition, mild forms of TCIRG1 osteopetrosis have been recently identified in adult patients, raising concerns about the risk of life-threatening complications during conventional therapy ${ }^{41}$ However, contrary to other inherited diseases treated with gene therapy, ${ }^{42}$ the development of novel strategies is required in osteopetrosis to overcome clinical limitations that may hamper gene therapy applicability ${ }^{43}$ For this reason, we developed a tailored approach for the treatment of TCIRG1-mutated osteopetrosis exploiting autologous HSPC gene correction and expansion.

Although previous studies have demonstrated the feasibility of gene therapy, ${ }^{12-15}$ its clinical applicability remains constrained by the scarcity of a BM niche and the limited amount of blood that can be drawn in these patients to collect circulating hematopoietic precursors. Remarkably, $\mathrm{CD}_{4} 4^{+}$cells isolated from $\mathrm{PB}$ of $\mathrm{ARO}$ patients have been reinfused successfully in two transplanted osteopetrotic patients with no engraftment or other complications, providing clinical evidence that circulating $\mathrm{CD} 34^{+}$cells can engraft and speed count recovery. ${ }^{16}$ In spite of these observations, no studies on the phenotypic composition and transcriptome of these spontaneously mobilized HSPC have been published. To assess relative frequencies and absolute counts/ $\mu \mathrm{L}$ of blood cellular components, we took advantage of a multiparametric flow cytometry analysis that allows the dissection of 23 different blood cell types, including HSPC, myeloid and lymphoid progenitors. ${ }^{27}$ Notably, HSC counts/uL were comparable to those observed in the BM of healthy children, supporting the feasibility of exploiting non-mobilized $\mathrm{PB}$ as an easily accessible source for hematopoietic stem cells in these patients.

These results were corroborated by the transcriptomic profile of circulating $\mathrm{CD} 34^{+}$cells from ARO patients, showing a positive enrichment for committed progenitor signatures, in particular for granulocyte-monocyte progenitor (GMP) cells. As recently described,${ }^{44}$ osteoclast defects can be rescued by monocytic cell transfusion in osteopetrotic mice. The simultaneous presence of HSC and myeloid lineage cells makes the circulating CD34 cells a favorable cell source for gene therapy. The heterogeneity of the population, containing both committed 
and primitive progenitors, would allow for an initial reconstitution after transplant sustained by differentiated progenitors, followed by a later output of transduced cells from long-term engrafting cells. ${ }^{45}$ The long-term survival capability of $\mathrm{PB}$ ARO-CD34 $4^{+}$cells is supported by our in vivo transplantation analyses, indicating that expanded gene-modified PB HSPC from ARO patients are able to maintain long-term multi-lineage engineered hematopoiesis both in primary and in secondary transplanted mice.

To further enhance the number of HSPC that can be collected by exchange transfusion, here we proposed an innovative strategy coupling transduction protocol with efficient ex vivo expansion of genetically modified HSC. We exploited the small molecule pyrimidoindole derivate UM171, that has been demonstrated to stimulate the in vitro expansion of human HSC and to enhance lentiviral transduction efficiency of $\mathrm{CB}$ derived $\mathrm{CD} 34^{+}$cells, maintaining their short- and long-term repopulating potential. ${ }^{19,20,38,46}$

The availability of UM171-expanded gene corrected CD34+ cells may allow the cryopreservation of corrected HSPC as backup for potential repeated administration. We can speculate that patients with low chimerism may benefit from repeated infusions in the absence of conditioning, as modeled in osteopetrotic mice. ${ }^{44,47}$ Remarkably, we demonstrated multi-lineage engraftment of $\mathrm{PB} \mathrm{CD} 34^{+}$ cells in immunodeficient mice upon ex vivo manipulation, including transduction and/or expansion. Of note, for the first time, we assessed the maintenance of long-term repopulating capacity in NSG secondary recipients of UM171-expanded CD $34^{+}$cells, indicating the presence of bona fide LT-HSC in the expanded and corrected cell population.

In order to pursue the clinical applicability of our approach, we designed a TCIRG1-expressing LV based on the vector approved and currently in use in the clinical trial for mucopolysaccharidosis type I (clinical trial TigetT10_MPSIH; clinicaltrials.gov identifier: NCT03488394)..$^{48,49}$ In our in vitro studies TCIRG1-corrected $\mathrm{CD}_{3} 4^{+}$with low VCN are able to resorb bone substrate, indicating that a limited number of corrected nuclei could provide for adequate protein levels in the mature multinucleated osteoclast. These results are in line with previous studies showing in vivo bone resorption in oc/oc mice with $1-3 \%$ of $\mathrm{BM}$ engraftment, likely due to the fusion of corrected hematopoietic progenitors to uncorrected cells. ${ }^{14,47,50}$

Importantly, the unregulated expression of TCIRG1 protein driven by the cellular ubiquitous PGK promoter does not impact on the clonogenic potential of HSPC, as shown by methylcellulose cultures.

In conclusion, here we provide a clinically applicable multi-step approach for autosomal recessive osteopetrosis based on the use of an optimized vector, an accessible HSPC source and reliable HSC expansion culture conditions. Our strategy may overcome all the major limitations related to the low number of $\mathrm{CD} 34^{+}$cells retrievable from ARO patients. Namely, PB CD34+ cells with primitive phenotype were easily collected and transduced with the corrective PGK.TCIRG1 vector. Then, the UM171based HSC expansion culture overcame the limited access to high blood volumes in severely affected children. These major improvements would allow the implementation of a clinical trial for autosomal recessive osteopetrosis in the next future and the exploitation of circulating $\mathrm{CD}_{3} 4^{+}$cells in other clinical conditions characterized by BM fibrosis.

\section{Disclosures}

No Conflicts of interest to disclose.

\section{Contributions}

$V C, S P, S S, L B R, E D, L S S$ and $L C$ performed experiments and analyzed the data; EP, EZ, GD and MS provided intellectual input, reagents, and protocols; IM, MB, PU and RC performed and analyzed RNAseq experiments; DM, PS, KD, ZK, $E U, A G, G M, A A, S L L, C C S$ and $A S$ provided patient samples and data; VC, SP, FF, CS and AV contributed to write the manuscript; $B G$ and $A V$ designed and coordinated the research. All authors critically revised the manuscript.

\section{Acknowledgments}

The authors would like to thank Miep Helfrich for helping with immunofluorescence and for valuable discussion. We would also like to thank ALEMBIC, an advanced microscopy laboratory established by IRCCS Ospedale San Raffaele and Università Vita-Salute San Raffaele.

\section{Funding}

This research was supported by a grant from the Telethon Foundation (TGT16C05) to $A V$ and partially by a fellowship from the European Calcified Tissue Society (ECTS) to VC.

\section{References}

1. Teti A, Teitelbaum SL. Congenital disorders of bone and blood. Bone. 2019;11:971-81.

2. Sobacchi C, Schulz A, Coxon FP, Villa A, Helfrich $\mathrm{MH}$. Osteopetrosis: genetics, treatment and new insights into osteoclast function. Nat Rev Endocrinol. 2013;9(9):522-536.

3. Palagano E, Menale C, Sobacchi C, Villa A. Genetics of osteopetrosis. Curr Osteoporos Rep. 2018;16(1):13-25

4. Frattini A, Orchard PJ, Sobacchi C, et al. Defects in TCIRG1 subunit of the vacuolar proton pump are responsible for a subset of human autosomal recessive osteopetrosis. Nat Genet. 2000;25(3):343-346.

5. Wu CC, Econs MJ, DiMeglio LA, et al Diagnosis and management of osteopetrosis: consensus guidelines from the osteopet- rosis working group. J Clin Endocrinol Metab. 2017;102(9):3111-3123.

6. Stepensky P, Grisariu S, Avni B, et al. Stem cell transplantation for osteopetrosis in patients beyond the age of 5 years. Blood Adv. 2019;3(6):862-868.

7. Teti A, Econs MJ. Osteopetroses, emphasizing potential approaches to treatment. Bone. 2017;102:50-59.

8. Steward CG. Hematopoietic stem cell transplantation for osteopetrosis. Pediatr Clin North Am. 2010;57(1):171-180.

9. Orchard PJ, Fasth AL, Le Rademacher JL, et al. Hematopoietic stem cell transplantation for infantile osteopetrosis. Blood. 2015; 126(2):270-276.

10. Schulz AS, Moshous D, Steward CG, Villa A, Sobacchi C. Osteopetrosis consensus guidelines for diagnosis, therapy and followup. ESID EBMT. 2015;1-35.
11. Chiesa R, Ruggeri A, Paviglianiti A, et al. Outcomes after unrelated umbilical cord blood transplantation for children with osteopetrosis. Biol Blood Marrow Transplant. 2016;22(11):1997-2002.

12. Johansson MK, De Vries TJ, Schoenmaker T, et al. Hematopoietic stem cell-targeted neonatal gene therapy reverses lethally progressive osteopetrosis in oc/oc mice. Blood. 2007;109(12):5178-5185.

13. Moscatelli I, Löfvall H, Schneider Thudium $\mathrm{C}$, et al. Targeting NSG mice engrafting cells with a clinically applicable lentiviral vector corrects osteoclasts in infantile malignant osteopetrosis. Hum Gene Ther. 2018; 29(8):938-949.

14. Moscatelli I, Thudium CS, Flores C, et al. Lentiviral gene transfer of TCIRG1 into peripheral blood CD34+ cells restores osteoclast function in infantile malignant 
osteopetrosis. Bone. 2013;57(1):1-9.

15.Löfvall H, Rothe M, Schambach A, Henriksen K, Richter J, Moscatelli I. Hematopoietic stem cell-targeted neonatal gene therapy with a clinically applicable lentiviral vector corrects osteopetrosis in oc/oc mice. Hum Gene Ther. 2019; 30(11):1395-1440.

16. Steward CG, Blair A, Moppett J, et al. High peripheral blood progenitor cell counts enable autologous backup before stem cell transplantation for malignant infantile osteopetrosis. Biol Blood Marrow Transplant. 2005;11(2):115-121.

17. Blin-Wakkach C, Rouleau M, Wakkach A. Roles of osteoclasts in the control of medullary hematopoietic niches. Arch Biochem Biophys. 2014;561:29-37.

18. Marcus JR, Fibach E, Aker M. Circulating myeloid and erythroid progenitor cells in malignant osteopetrosis. Acta Haematol. 1982;67(3):185-189.

19. Zonari E, Desantis G, Petrillo C, et al. Efficient ex vivo engineering and expansion of highly purified human hematopoietic stem and progenitor cell populations for gene therapy. Stem Cell Reports. 2017; 8(4):977-990.

20. Fares I, Chagraoui J, Gareau Y, et al. Pyrimidoindole derivatives are agonists of human hematopoietic stem cell self-renewal. Science. 2014;345(6203):1509-1512.

21. Mazzolari E, Forino C, Razza A, Porta F, Villa A, Notarangelo LD. A single-center experience in 20 patients with infantile malignant osteopetrosis. Am J Hematol. 2009:84(8):473-479.

22. Aiuti A, Biasco L, Scaramuzza S, et al. Lentiviral hematopoietic stem cell gene therapy in patients with Wiskott-Aldrich syndrome. Science. 2013;341(6148):12331511233151.

23. Biffi A, Montini E, Lorioli L, et al. Lentiviral hematopoietic stem cell gene therapy benefits metachromatic leukodystrophy. Science. 2013;341(6148):1233158-1233158.

24. Coxon FP. Fluorescence imaging of osteoclasts using confocal microscopy. Methods Mol Biol. 2012;816:401-424.

25. Menale C, Campodoni E, Palagano E, et al. Mesenchymal stromal cell-seeded biomimetic scaffolds as a factory of soluble RANKL in Rankl-deficient osteopetrosis. Stem Cells Transl Med. 2019;8(1):22-34.

26. Cimato TR, Furlage RL, Conway A, Wallace PK. Simultaneous measurement of human hematopoietic stem and progenitor cells in blood using multicolor flow cytometry.
Cytometry B Clin Cytom. 2016;90(5):415423

27. Basso-Ricci L, Scala S, Milani R, et al. Multiparametric whole blood dissection: one-shot comprehensive picture of the human hematopoietic system. Cytometry A. 2017;91(10):952-965.

28. Ramalho-Santos M, Yoon S, Matsuzaki Y, Mulligan RC, Melton DA. "Stemness": transcriptional profiling of embryonic and adult stem cells. Science. 2002;298(5593):597-600.

29. Jaatinen T, Hemmoranta H, Hautaniemi S, et al. Global gene expression profile of human cord blood-derived CD133+ cells. Stem Cells. 2005;24(3):631-641.

30. Eppert K, Takenaka K, Lechman ER, et al. Stem cell gene expression programs influence clinical outcome in human leukemia. Nat Med. 2011;17(9):1086-1094.

31. Georgantas RW, Tanadve V, Malehorn M, et al. Microarray and serial analysis of gene expression analyses identify known and novel transcripts overexpressed in hematopoietic stem cells. Cancer Res. 2004; 64(13):4434-4441.

32. Doulatov S, Vo LT, Chou SS, et al. Induction of multipotential hematopoietic progenitors from human pluripotent stem cells via respecification of lineage-restricted precursors. Cell Stem Cell. 2013;13(4):459-470.

33. Laurenti E, Doulatov S, Zandi S, et al. The transcriptional architecture of early human hematopoiesis identifies multilevel control of lymphoid commitment. Nat Immunol. 2013;14(7):756-763

34. Park IK, He Y, Lin F, et al. Differential gene expression profiling of adult murine hematopoietic stem cells. Blood. 2002; 99(2):488-498.

35. Zheng S, Papalexi E, Butler A, Stephenson W, Satija R. Molecular transitions in early progenitors during human cord blood hematopoiesis. Mol Syst Biol. 2018; 14(3):e8041.

36. Clien L, Kostadraia M, Martens JHA, et al. Transcriptional diversity during lineage commitment of human blood progenitors. Science. 2014;345(6204):1251033.

37. Amendola M, Venneri MA, Biffi A, Vigna E, Naldini L. Coordinate dual-gene transgenesis by lentiviral vectors carrying synthetic bidirectional promoters. Nat Biotechnol. 2005;23(1):108-116

38. Fares I, Chagraoui J, Lehnertz B, et al. EPCR expression marks UM171-expanded CD34+ cord blood stem cells. Blood. 2017; 129(25):3344-3351.

39. Cohen S, Roy J, Lachance S, et al. Single
UM171 expanded cord blood permits transplantation of better HLA matched cords with excellent GvHD relapse free survival. Blood. 2018;132(Suppl 1):4658.

40. Askmyr M, Flores C, Fasth A, Richter J. Prospects for gene therapy of osteopetrosis. Curr Gene Ther. 2009;9(3):150-159.

41. Palagano E, Blair HC, Pangrazio A, et al Buried in the middle but guilty: intronic mutations in the TCIRG1 gene cause human autosomal recessive osteopetrosis. J Bone Miner Res. 2015;30(10):1814-1821.

42. Gawthorpe P. Gene therapy. Nurs Stand. 2003;17(33):29.

43. Penna S, Capo V, Palagano E, Sobacchi C, Villa A. One disease, many genes: implications for the treatment of osteopetroses. Front Endocrinol (Lausanne). 2019;10:85.

44. Jacome-Galarza CE, Percin GI, Muller IT, et al. Developmental origin, functional maintenance and genetic rescue of osteoclasts. Nature. 2019;568(7753):541-545.

45. Scala S, Basso-Ricci L, Dionisio F, et al Dynamics of genetically engineered hematopoietic stem and progenitor cells after autologous transplantation in humans. Nat Med. 2018;24(11):1683-1690.

46. Ngom M, Imren S, Maetzig T, et al. UM171 enhances lentiviral gene transfer and recovery of primitive human hematopoietic cells. Mol Ther Methods Clin Dev. 2018;10:156164.

47. Flores C, De Vries TJ, Moscatelli I, et al. Nonablative neonatal bone marrow transplantation rapidly reverses severe murine osteopetrosis despite low-level engraftment and lack of selective expansion of the osteoclastic lineage. J Bone Miner Res. 2010; 25(9):2069-2077.

48. Gentner B, Bernardo ME, Zonari E, et al. Exvivo gene therapy for Hurler disease: initial results from a phase I/II clinical study. Mol Ther. 2019;27(4S1):abstr 2.

49. Squeri G, Passerini L, Ferro F, et al. Targeting a pre-existing anti-transgene $T$ cell response for effective gene therapy of MPS-I in the mouse model of the disease. Mol Ther 2019;27(7):1215-1227.

50. Thudium CS, Moscatelli I, Löfvall $\mathrm{H}$, et al Regulation and function of lentiviral vectormediated TCIRG1 expression in osteoclasts from patients with infantile malignant osteopetrosis: implications for gene therapy Calcif Tissue Int. 2016;99(6):638-648.

51. Den Dunnen JT, Dalgleish R, Maglott DR, et al. HGVS recommendations for the description of sequence variants: 2016 update. Hum Mutat. 2016;37:564-569. 